\title{
INTERNAL VERIFICATION OF COATING QUALITY IN CONFORMITY WITH THE REQUIREMENTS OF THE EN 1090 STANDARD
}

\author{
Marko HORVAT, Dunja SRPAK, Veljko KONDIĆ, Igor PUS
}

\begin{abstract}
The requirements for the quality of protection on metal structures in terms of durability, reliability and efficiency require from the manufacturer to define certain procedures and verification of anticorrosion protection activities. Today, the criteria used to evaluate the success of the protection and the general quality of the structure are the criteria listed in the EN 1090 standard and in the compatible standards related to the realization and protection of metal structures. The article briefly describes the basis of the requirements of the standard, the eligibility criteria for the protection of structures and it also gives a practical example of the verification process through preparation, implementation and control.
\end{abstract}

Keywords: EN 1090; materials; metal protection; metal structures

\section{INTRODUCTION}

The quality of protection on metal structures in terms of durability, reliability and efficiency and the verification of anticorrosion protection activities are widely studied in scientific papers. Thereby, different coatings are researched, such as the polyetheramide (PEtA) coatings on carbon steel in [1], ecologically acceptable waterborne and multi-layered coatings in [2], or different super-hydrophobic coating systems obtained by different preparation technologies in [3]. In [4], authors demonstrate the use of different concentrations of 8-hydroxyquinoline (8-HQ) in epoxy coatings in order to detect the early stages of corrosion on metal surfaces. The anti-graffiti properties of a polyurethane organic coating are studied in [5], while the protection of buried metallic structures against corrosion by using coatings combined with cathodic protection is researched in [6]. The long-term efficacy and performance of protective coatings are tested in [7], using the wet and dry cycles of accelerated weathering and corrosion test protocols.

At the beginning of this research, the assumption was that the internal quality verification of coatings on structure materials depends mostly on the characteristics of the coating quality, surface preparation and application technology. These factors are essential for the compliance with the requirements of the EN 1090 and the related norms.

This paper is organized as follows. First, a general description of important factors influencing the quality of metal protection is given, as well as the technology of metal protection by organic coatings and certain guidance for the selection of effective organic coatings. In the next section, the procedure of internal verification implementation is described. Furthermore, the results of internal quality verification on a three-component coating system are presented. Finally, the most important conclusions are given at the end of the paper.

\section{PROTECTION OF METAL AGAINST CORROSION}

The application of the EN 1090 standard is related to the requirements for the conformity assessment of structural components for the construction of steel (and aluminum) structures and it covers all constituent parts or elements that can have an important impact on the construction (construction object). It defines the quality requirements that need to be met by the manufacturer, in all segments of its emergence: design, manufacture and testing.

As an important segment in the production of steel structures, the procedures related to the anticorrosion protection technology are specifically prescribed and described in Chapter 10 of this Standard, as well as all relevant standards used in the implementation of protection. Complying with the prescribed procedures is important for guaranteeing a satisfactory anticorrosion protection performance and the certification of the system of factory control. A similar verification (internal or external) is carried out on other key parts of the manufacturing process: cutting, drilling, mechanical joining, etc.

\subsection{General View of Metal Protection}

The corrosion of metals can be prevented by inhibiting (by preventing media aggression), by shifting the potential of local anodes in a negative sense (cathodic protection), by passivating the metal surface (anodic protection), and the most often method in practice is the separation of the metal surface from aggressive media by coating. In aggressive media and at higher temperatures, metals are required to be coated with noble metals by the diffusion method. Where less protection is required, it is sufficient to oxidize, chrome or phosphatize the metal surface. At low temperatures and with no mechanical load on the surface, organic coatings provide good protection.

\subsection{The Purpose of Organic Coatings in the Metal Protection System}

Most metal surfaces found on constructions and industrial structures are today generally protected by coating with certain organic materials, which can be:

- coating based on oil-paints and lacquers,

- coatings of cellulose ester lacquer, 
- bituminous coatings and linings and

- coatings made from synthetic plastic resin and vinyl polymerisers.

The purpose of organic coatings is primarily to protect metallic surfaces from corrosion processes, but also to give a better appearance of the construction and plant. Apart from corrosion resistance, these coatings should include certain hardness, elasticity, impact resistance, friction resistance, mechanical strength, thermal stability, water- and steamimpermeability, longevity, etc.

One of the most important features of organic coatings is their duration. Although it depends on the characteristics of metal that is to be protected, of surface roughness, coating composition and outdoor atmosphere, very important is the procedure of applying the coating [8].

\subsection{Technology of Metal Protection by Organic Coatings}

Anticorrosion coating in multiple layers with different features is preferred in order to achieve a successful and complete protection of the construction or plant. Furthermore, it is important to know the technology of applying a particular coating to ensure that the coating material will meet all the requirements expected on a metal surface or at least part of them.

The technological coating application process on the metal surface comprises [9]:

1. the preparation of the metal surface - cleaning and conditioning the surface state,

2. applying of coating materials and

3. finishing (drying / hardening of the coating).

If the technological process is not carried out properly, the desired protective effect cannot be achieved even if the optimum coating system is chosen [9].

The degrees of surface preparation and metal cleaning, as well as the appearance of the surface prior and after the preparation are defined by corresponding standards [10]. For the practical implementation of this technological process, it is necessary to have adequate equipment, knowledge and quality assurance.

Coating agents can be applied on the prepared metal surface by brushes, blades, rollers or by immersing, spraying and electrophoresis.

The base coating as the most important coating layer for preventing corrosion should be capillary active to penetrate into all pores on the metal surface it protects. Additionally, high adhesion to metal, protrusion resistance and nonporousness are required. The task of covering coatings is to ensure the quality of the basic coating from mechanical and atmospheric impacts and chemical destruction.

Therefore, an important parameter in protecting metal surfaces of the construction is coating thickness. Furthermore, drying time $(t)$ is very important and depending on the thickness of the coating $(d)$, it can be calculated by using (1):
$t=C \cdot a^{d}$,

where $C$ and $a$ are the constant values, but the value of $a$ is always greater than one.

\subsection{Selection of Effective Organic Coatings}

The selection of effective corrosion protection coatings requires the consideration of a wide range of influencing factors to ensure an optimal economic and technical solution. The most important factors to be analyzed are [10]:

- the corrosivity of the environment,

- the type of surface to be protected against corrosion,

- the durability of the coating system,

- coating application technology.

\subsubsection{Corrosion of the Environment}

The corrosivity of the environment encompasses the conditions to which the metal structure will be exposed during the exploitation, such as: moisture and temperature, the presence of UV radiation, exposure to chemical agents and mechanical damage (stroke, abrasion, etc.).

The international standard ISO 12944 provides a classification of corrosion for atmospheric conditions, soil and water, with the explanations about the meaning of these categories from very low and low to high and very high.

\subsubsection{Type of the Protected Surface}

When choosing a coating system, it is important to know the materials which the construction is made of, because that determines the degree of surface preparation, the coating material and the overall thickness of the film.

\subsubsection{Durability of the Coating System}

The durability of the coating system implies a period from the moment of application of the first coating to the moment of first maintenance. The standard ISO 12944 specifies three time periods that categorize the durability of the coating system as $\mathrm{L}-$ low ( 2 to 5 years), $\mathrm{M}$ - medium ( 5 to 15 years) and $\mathrm{H}$ - high (more than 15 years).

\subsubsection{Technology and Dynamics of the Application Process}

The coating system on the constructions has to be applied according to the technological process of realization. The coating application technology must take into account the surface preparation time and drying time relative to the air temperature and humidity, as well as the intervals between applying the different layers of coatings.

\section{IMPLEMENTATION OF THE INTERNAL VERIFICATION OF THE COATING QUALITY}

The task of internal verification is to prove the ability to implement technology according to the specific requirements 
of a particular standard (or group of norms). The results of the verification of the process (technology) guarantee the quality of the works to both the contractor and investor, when performed according to the rules of the profession. The contractor can also use the resulting qualitative and quantitative data to improve the implementation of a certain technology.

The internal verification of the coating quality according to the EN 1090 norm was carried out on test specimens with the dimensions of $250 \times 150 \times 4 \mathrm{~mm}$ (material S355J2 $+\mathrm{N}$ ). The three-component system (zinc epoxy base NA + epoxy $\mathrm{NA}+$ polyurethane $\mathrm{BO}$ ) was applied according to the relevant norms and guidelines of the color manufactures (surface preparation, application conditions, minimum dry film thickness, measurement method). The expected protection system is categorized as $\mathrm{C} 3-\mathrm{H}$.

Surface preparation is performed by sandblasting (quartz sand), in Sa 2.5 quality (very thorough abrasive blast cleaning) as defined by the EN ISO 8501 norm. Surface preparation control (cleaning and roughness assurance) is provided through the visual control of purity (according to visual etalons - photographs in the EN 8501 norm) as shown in Fig. 1 and by roughness measurement. Measurement was carried out in 10 points and the results are given in Fig. 2. The expected roughness is at least $40 \mu \mathrm{m}\left(R_{Z}=40 \mu \mathrm{m}\right)$.
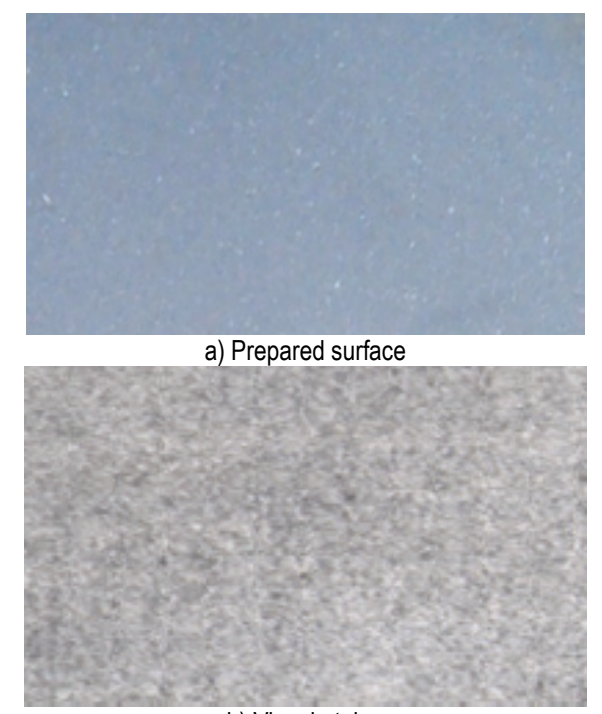

b) Visual etalon

Figure 1 The view of the surface after sandblasting

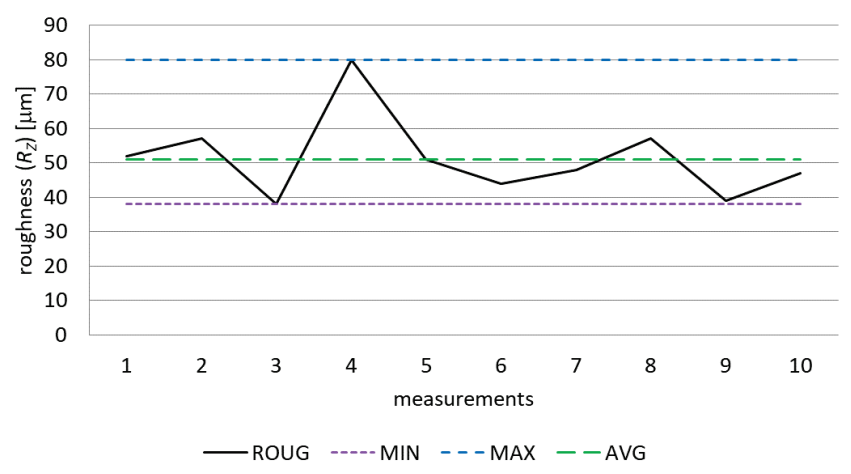

Figure 2 Surface roughness measurement results
CINK-EPOXY solvent-based primer is applied as a first coat on the prepared surface (cleansing + roughness), performed according to the rules of the profession and the recommendations of the paint manufacturer. Fig. 3 shows the appearance after applying the first layer of coating and Fig. 4 shows the results of dry film thickness measurements. As recommended by the manufacturer, the expected value of dry film thickness after the first coat for this three-component system is $40 \mu \mathrm{m}$.

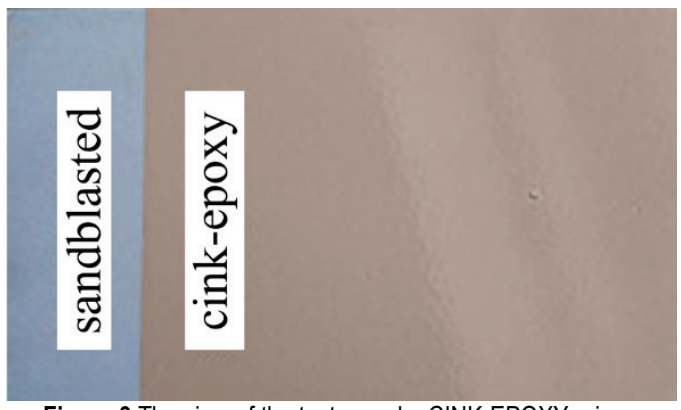

Figure 3 The view of the test sample: CINK-EPOXY primer

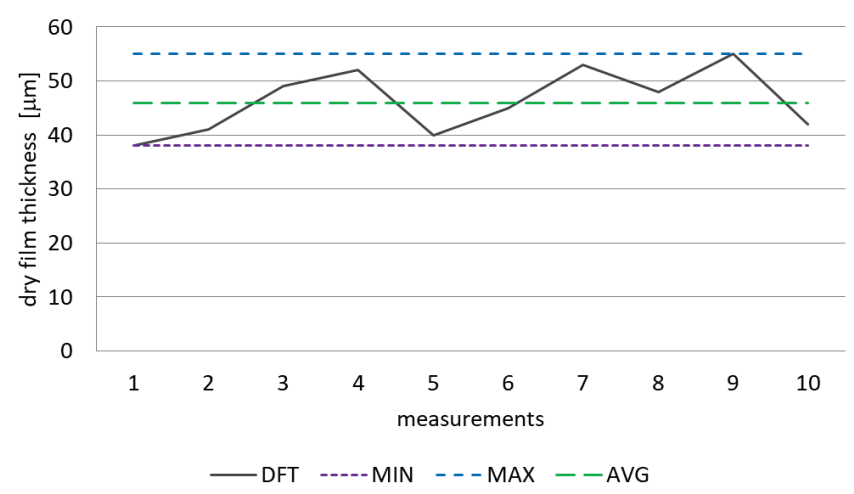

Figure 4 Dry film thickness measurement - CINK-EPOXY primer

The second component of this coating system is the EPOXY coating, also solvent-based. The coating was performed under the same conditions as the first layer, and Fig. 5 and 6 show the results. As recommended by the manufacturer, the expected value of the dry film thickness of the interlayer is $80 \mu \mathrm{m}$ and the total value is $120 \mu \mathrm{m}$.

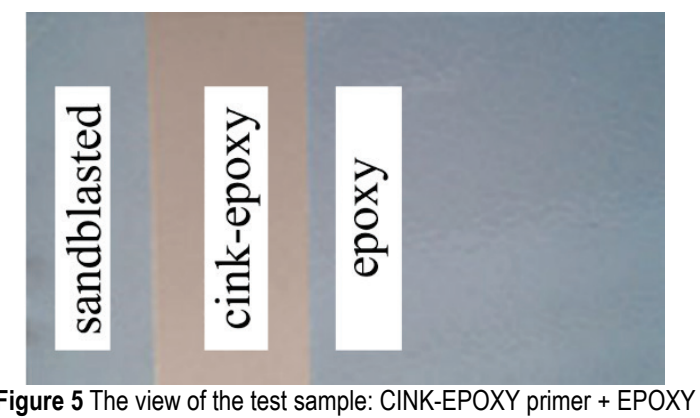

The anticorrosion protection system ends with a POLIURETHANE solvent-based coating. The recommended dry film thickness is $60 \mu \mathrm{m}$ (total thickness is $180 \mu \mathrm{m})$. Fig. 7 shows a test plate with a final layer and Fig. 
8 the results of dry layer thickness measurement after a threecomponent anticorrosion protection.

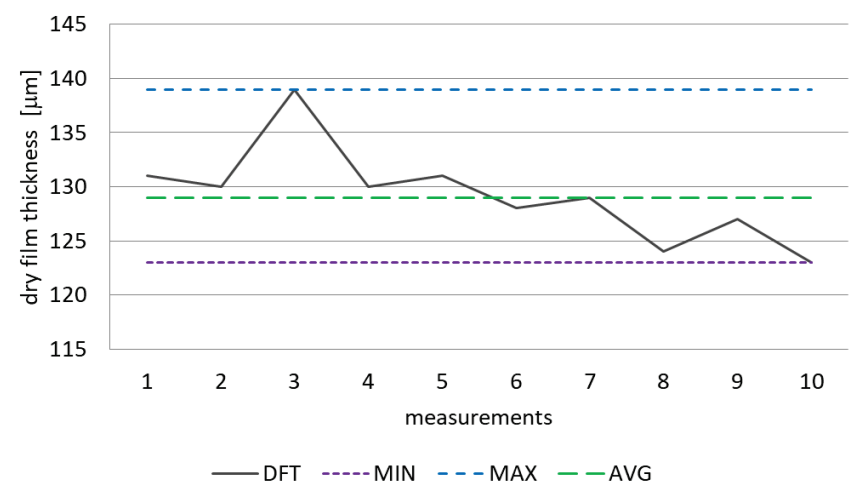

Figure 6 Dry film thickness measurement - CINK-EPOXY primer + EPOXY

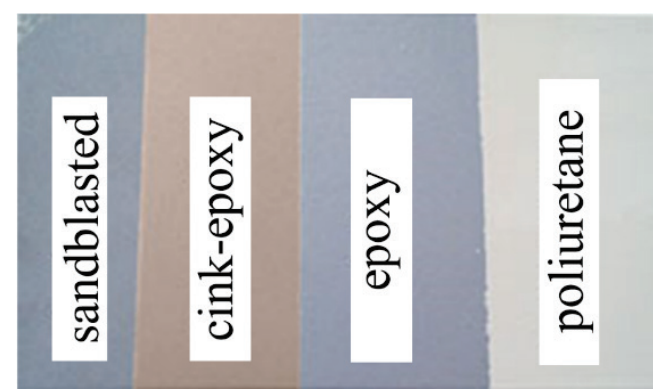

Figure 7 The view of the test sample: CINK-EPOXY primer + EPOXY + POLIURETHANE

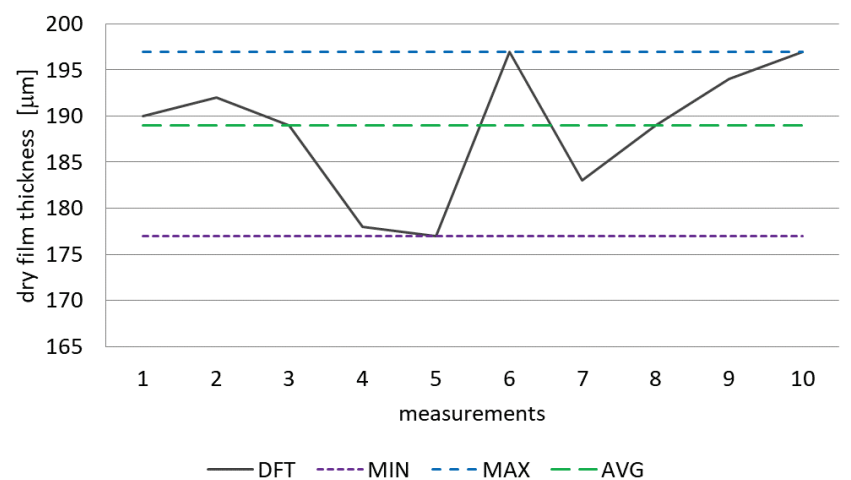

Figure 8 Dry film thickness measurement - CINK-EPOXY primer + EPOXY + POLIURETHANE

The test results (roughness and dry film thickness) confirm the expected results in accordance with the relevant norms and recommendations of the manufacturer of anticorrosion protection products. The results obtained by measuring are within the expected values and within the tolerance limits recommended by the standard. This confirms the successful verification of the anticorrosion protection technology and quality assurance in the future application of the three-component anticorrosion protection system on steel structures.

\section{CONCLUSION}

By entering the EU, Croatia has adopted many regulations and standards, as well as the standard for the manufacture of steel and aluminum consoles, EN 1090. This standard defines the quality requirements that the manufacturer must meet when designing, producing and testing steel and aluminum structures and components parts. Each of the aforementioned segments has to be proven through some form of documented information (record, operating instructions, verification of the procedure, etc.).

The importance of anticorrosion protection, as well as all related activities, is highlighted in EN 1090 through a separate chapter, along with a description of the basic requirements and implementation criteria, with particular emphasis on all current and relevant standards that apply to the preparation, implementation and quality control of the anticorrosive protection. This paper presents an example of the verification of the quality of anticorrosion protection by internal procedure - examination. Verification was carried out on the test sample with the standard color system $(2+1)$ and with a simple way of controlling the quality of the finished works as it is usually the most commonly used for the protection of steel structures. This type of verification serves to the manufacturer as a confirmation of the performance of the protection technology (as required by the relevant documents) and reduces the possibility of errors occurring during the repetition of this and similar processes in the past. Similar verification (internal or independent) is carried out for other processes within the production (e.g. drilling, mechanical tightening, cutting, etc.), all for making the construction of the EN 1090 standard.

Note: This research was partially presented, as a poster, at the International Conference MATRIB 2017 (29 June - 2 July 2017, Vela Luka, Croatia).

\section{REFERENCES}

[1] Alam, M., Alandis, N. M., Ahmad, N., \& Alam, M. A. (2018). Corrosion Protection of Carbon Steel by Pongamia glabra OilBased Polyetheramide Coatings. International Journal of Electrochemical Science, 13(3), 3124-3135. https://doi.org/10.20964/2018.03.52

[2] Aracic, S., Krumes, D., Maticevic, T., \& Vilovcevic, I. (2010). Testing the durability of ecologic coats in the protection of metals from corrosion. Tehnički vjesnik, 17(3), 343-346.

[3] Cao Z. F., Qiu P., Chen P., Wen X., Liu G., Wang S., \& Zhong H. (2017). Super-hydrophobic coating used in corrosion protection of metal material: review, discussion and prospects. Metallurgical Research and Technology, 114(2), p. 11.

[4] Roshan, S., Dariani, A. A. S., \& Mokhtari, J. (2018). Monitoring underlying epoxy-coated St-37 corrosion via 8hydroxyquinoline as a fluorescent indicator. Applied Surface Science, 440, 880-888. https://doi.org/10.1016/j.apsusc.2018.01.188

[5] Rossi, S., Fedel, M., Petrolli, S., \& Deflorian, F. (2017). Characterization of the Anti-Graffiti Properties of Powder Organic Coatings Applied in Train Field. Coatings, 7(5), Art. 67. 
[6] Mandavi, F., Forsyth, M., \& Tan, M. Y. J. (2017). Techniques for testing and monitoring the cathodic disbondment of organic coatings: An overview of major obstacles and innovations. Progress in Organic Coatings, 105, 163-175. https://doi.org/10.1016/j.porgcoat.2016.11.034

[7] Hinderliter, B. R. \& Sapper, E. D. (2015). Water concentration distribution in coatings during accelerated weathering protocols. Journal of Coatings Technology and Research, 12(3), 477-487. https://doi.org/10.1007/s11998-015-9661-8

[8] Esih, I. \& Dugi, Z. (2003). Osnove površinske zaštite. Fakultet strojarstva i brodogradnje, Zagreb.

[9] Aračić, S. (2003). Tehnologija površinske zaštite. Fakultet strojarstva i brodogradnje, Zagreb.

[10] (2017). How to select the right paint system. Guidelines for coating protection in accordance with ISO 12944. Hempel Coatings ISO-brochure_FI_20171221.pdf (in Croatian) LTD, Umag.

[11] EN 1090-2:2008. Execution of steel structures and aluminium structures -- Part 2: Technical requirements for steel structures (EN 1090-2:2008+A1:2011)

\section{Authors' contacts:}

Marko HORVAT, PhD student, dipl. ing. mech., Lecturer Sveučilište Sjever, Sveučilišni centar Varaždin

104. brigade 3,42000 Varaždin, Croatia

E-mail: marko.horvat@unin.hr

Dunja SRPAK, PhD, dipl. ing. el., Lecturer (Corresponding author)

Sveučilište Sjever, Sveučilišni centar Varaždin

104. brigade 3, 42000 Varaždin, Croatia

E-mail: dunja.srpak@unin.hr

Veljko KONDIĆ, PhD student, mag. ing. mech., Lecturer Sveučilište Sjever, Sveučilišni centar Varaždin 104. brigade 3, 42000 Varaždin, Croatia

E-mail: veljko.kondic@unin.hr

Igor PUS, MBA-univ. spec. oec., dipl. ing. mech. Consultus d.0.0.

VIII. Vrbik 26, 10000 Zagreb, Croatia

E-mail: igor.pus@consultus.hr 